\title{
Parental education and guided self management of asthma or wheeze in pre-school children was not effective
}

\author{
Stevens CA, Wesseldine LJ, Couriel JM, et al. Parental education and guided self-management of asthma and wheezing in the \\ pre-school child: a randomised controlled trial. Thorax 2002 Jan;57:39-44.
}

\section{QUESTION: What is the effectiveness of an educational intervention for parents of pre-school children who have had a recent episode of acute asthma?}

\section{Design}

Randomised \{allocation concealed $*\}$, blinded \{clinicians, participants, data collectors, and outcome assessors $\}+*$ controlled trial with 1 year of follow up.

\section{Setting}

2 children's hospitals in England, UK (Leicester and Manchester).

\section{Patients}

200 children between 18 months and 5 years (median age $32 \mathrm{mo}, 67 \%$ boys) were recruited at the time of admission to a children's ward or at attendance at an accident and emergency department (AED) or children's assessment unit (CAU) with a primary diagnosis of acute severe asthma or wheezing. Follow up was $94 \%$.

\section{Intervention}

Children were allocated to an intervention group $(\mathrm{n}=99)$ or a control group $(n=101)$. The intervention included a general educational booklet about asthma in pre-school children that discussed symptoms, triggers and how to avoid them, and asthma treatment; a written, guided self management plan with instructions on when to use rescue medication, what to do if asthma worsens, and signs of severe asthma and appropriate action to take; and two 20 minute structured individual educational sessions (1 mo apart) given by a specialist respiratory nurse. The control group received usual medical and nursing care.

\section{Main outcome measures}

Rates of general practitioner (GP) consultations, hospital readmissions, and attendances at an AED or CAU; children's perceived disability; care giver's quality of life; and parental knowledge of asthma.

\section{Main results}

Analysis was by intention to treat. The intervention and control groups did not differ for the mean number of GP consultations per child per year (3.87 v 4.13, mean difference $-0.26,95 \% \mathrm{CI}-1.34$ to $0.81, \mathrm{p}=0.63$ ) or rates of hospital readmissions or AED or CAU attendances (table). Groups did not differ for children's perceived disability, care giver's quality of life, parental knowledge of asthma, or confidence of parents or care givers in caring for the child, and no appreciable trends existed in favour of treatment for any of these measures.

\section{Conclusion}

For parents of pre-school children who have had a recent hospital visit for asthma or wheeze, an educational intervention with a written, guided self management plan was not effective.

*See glossary.

†Information provided by author.

Source of funding: NHS Executive Mother and Child Health Programme.

For correspondence: Professor M Silverman, University of Leicester, Leicester, UK. ms70@le.ac.uk

An educational intervention and guided self management plan v usual care for parents of pre-school children after a recent hospital visit for asthma or wheeze:

\begin{tabular}{|c|c|c|c|c|}
\hline Outcomes at 1 year & Intervention & Usual care & RRI (95\% Cl) & NNH \\
\hline $\begin{array}{l}\text { Hospital } \\
\quad \text { readmissions }\end{array}$ & $26 \%$ & $19 \%$ & $40 \%(-17$ to 135$)$ & Not significant \\
\hline & & & $\operatorname{RRR}(\mathrm{Cl})$ & NNT \\
\hline $\begin{array}{l}\text { AED or CAU } \\
\text { attendances }\end{array}$ & $17 \%$ & $19 \%$ & $9 \%(-64$ to 49$)$ & Not significant \\
\hline
\end{tabular}
glossary; RRI, RRR, NNH, NNT, and Cl calculated from data in article.

\section{COMMENTARY}

Why did this well designed study by Stevens et al yield a negative result? Children with higher baseline morbidity were appropriately selected, the educational session reviewed key elements, and the power was acceptable. Perhaps the magnitude of difference in effects sought was unrealistically large, although smaller effects may not warrant the organisational effort required for the intervention.

Four other factors may have contributed to the negative result. Firstly, the evidence supporting the key element of the intervention - administration of oral prednisolone with asthma worsening - is based on a single, dated randomised controlled trial. ${ }^{1}$ Thus, the recommended management strategy may be ineffective.

Secondly, the treating physician's endorsement of the recommendations made at the educational sessions is a key element for patient adherence. ${ }^{2}$ In this study, $10 \%$ of intervention-group patients were not prescribed short acting inhaled $\beta_{2}$ agonists; no mention is made about the percentage of patients actually prescribed oral prednisolone for the next cold.

Thirdly, the authors provide little information about parental compliance with instructions on how to respond to asthma worsening.

Fourthly, while visits for GP re-evaluation are clearly part of resource use, combining them with repeated attendance to the ED and the rate of unscheduled GP consultations would reduce the power of the study to detect differences in the latter events.

The main lesson to be drawn from this well designed trial is that one size does not fit all (ie, what works for older children and adults does not necessarily apply to younger children). More trials are needed to address the special needs of pre-school aged children.

Francine Ducharme, MD, MSc McGill University/Montreal Children's Hospital Montreal, Quebec, Canada

1 McKean M, Ducharme FM. Inhaled steroids for episodic viral wheeze of childhood. Cochrane Database Syst Rev 2000;(2):CD001107.

Haby MM, Waters E, Robertson CF, et al. Interventions for educating children who have attended the emergency room for asthma. Cochrane Database Syst Reo 2001;(1):CD001290. 